\title{
Reduction of Carbon Dioxide Emission in Thermal Power Plants using Fire Fly Optimization Technique
}

\author{
K.Vinod Kumar \\ Department of Electrical \\ Engineering \\ NIT Warangal, India
}

\author{
Ch.Divya Saroja \\ Department of Electrical \\ Engineering \\ NIT Warangal, India
}

\author{
K.Mahesh \\ Department of Electrical \\ Engineering \\ NIT Warangal, India
}

\begin{abstract}
Global Warming is the greatest challenge that the world is facing today. It is very important to take preventive measures before this problem poses a serious threat to the mankind. Power Plants play a major role in green house gas emissions. Nearly $21.3 \%$ of green house gases are emitted by these power plants alone. In this paper we try to propose a computational approach to reduce these carbon dioxide emissions by using Fire Fly Optimization Technique. The proposed optimization technique is better than other conventional optimization techniques in terms of computational time and number of iterations. It also shows that the method is practically applicable in real time. The technique was applied to a three generator and six generator systems for different load demands for validation. To check the quality of the solution the results are being compared with the conventional optimization algorithms.
\end{abstract}

\section{Keywords}

Fire Fly Optimization Algorithm, Carbon dioxide emission, Green House Gases, Thermal Power Plant, Fossil Fuels.

\section{INTRODUCTION}

Electricity has become one of the basic needs of the world. Presently there is already a huge demand for power and with the emergence of new industries and the increase of consumers of electricity; this demand is expected to grow even more in the next two decades. Even though non-conventional sources of energy like hydel and nuclear are being involved, still the major share of the power is contributed by thermal power plants only as the reliability and safety factor is higher and thermal power plants are suited for base load demands.

The rising concentrations of green house gases (GHGs) of anthropogenic origin in the atmosphere such as Carbon Dioxide $\left(\mathrm{CO}_{2}\right)$, Methane $\left(\mathrm{CH}_{4}\right)$, and Nitrous Oxide $\left(\mathrm{N}_{2} \mathrm{O}\right)$ have increased, since the late $19^{\text {th }}$ century. According to the Third Assessment Report (TAR) of the inter government Panel on climatic changes, because of increase in the concentration of the green house gases in the atmosphere in the last 100 years, the mean surface temperature has risen by $0.4-0.8^{0} \mathrm{C}$ globally. The precipitation has become spatially variable and the intensity and frequency of extreme events has increased. The sea level has also risen at an average rate of 1-2 $\mathrm{mm}$ during this period. This continuous increase in the concentration of the green house gases will result in more severe changes in the eco system and may cause imbalance in the nature. In this industrial era, many activities of the man emit the green house gases into the atmosphere, mainly through burning fossil fuels and deforestation. The carbon dioxide emissions by burning of fossil fuels can be classified into seven categories namely, Solid fuels
$35 \%$, liquid fuels $36 \%$, gaseous fuels $20 \%$, flaring gas $<1 \%$, cement production $3 \%$, non-fuel hydrocarbons $<1 \%$, the international bunkers of shipping and air transport $4 \%$. To minimize these emission researchers have proposed solutions that use the artificial intelligence techniques.

Recent advancements in computational intelligence, especially in the area of evolutionary computing, made scientists realize that nature is a great inspiration to design techniques which are used in development of intelligent systems and algorithms. Researchers started to concentrate on the nature inspired algorithms which mimic the natural phenomenon to develop intelligent algorithms. Some of the nature inspired algorithms include the Genetic Algorithm (GA), Artificial Bee Colony Algorithm (ABC), Monkey Search Algorithm (MS), Bacterial Foraging, Big Bang Big Crunch Algorithm (BBBC), Fire Fly Algorithm. These algorithms proved to be worth in solving many problems in engineering. Some of the areas where these nature inspired algorithms have been phenomenal include Economic Load Dispatch (ELD) Problem, Unit Commitment (UC) Problem in power systems, Tuning control gains of a controller in a process in Control Engineering.

Fire flies also called as Lighting Bugs are one of the nature's fascinating creatures. These flies are capable of producing light using their special photogenic organs situated very close to their body surface. They use these light emitting capability for various reasons like social behaviour, prey attraction, warning signal when a predator arrives, organizational behaviour and many more. Lot of research is being done on these fire flies in bio-chemical as well as engineering for various reasons. As researchers succeeded in finding solutions to many optimization problems by mimicking many naturally inspired patterns like Ant Colony Optimization, Artificial Bees Colony Optimization, Monkey Search Optimization etc,. They succeeded in applying the Fire Fly behaviour to optimization problems hence getting some good results.

In this paper we attempt to apply the Fire Fly Optimization Algorithm to reduce the carbon dioxide emission from thermal power stations. Rest of the paper is organized as follows: section 2 we discuss about global warming, problem formulation in section 3, Fire fly Algorithm in section 4 and results \& evaluation in section 5 .

\section{GLOBAL WARMING}

The fuel used in thermal power plants are fossil fuels and the majorly used fossil fuel is coal. Use of fossil fuels in thermal power plants gives rise to two serious environmental concerns: one being the possible exhaustion of coal and other which is even more significant is Global Warming. 
Global warming is the increase in surface and sub-surface temperatures across the earth. This phenomenon leads to a situation where the global balance between various eco-systems is disturbed. It has been calculated that the average temperatures have risen by around $0.75{ }^{\circ} \mathrm{C}$ with an uncertainty factor because the response of all biospheres on earth towards global warming is not the same. The Tundra or polar ice caps are melting as a result and has led to increase in ocean levels.

The relation between thermal power plants and the Global warming is explained by another concept called Green house effect. Certain gases like carbon dioxide and water vapor capture the heat radiated by the earth's surface back to the atmosphere and lead to what is called warming. This phenomenon by which the gases are not allowing infra-red radiations from the surface to leave the atmosphere is called Green-house effect and the gases are called Green-house gases. The major Green-house gas is $\mathrm{CO}_{2}$. The carbon dioxide content in the atmosphere has seen a rapid increase since 1880 since the beginning of the Industrial revolution . The major contributors to $\mathrm{CO}_{2}$ in the atmosphere are due to human activities and are emissions from power plants. Nature has its own way to counter this increase. The $\mathrm{CO}_{2}$ in the atmosphere is used in the photosynthesis process by plants and carbon dioxide is absorbed by the vast area of expanse of water in the form of seas but under an optimum condition of temperature. Due to deforestation the situation has become more acute and the solubility in oceans is also decreased by the cause which is the global warming itself. Hence it has become very essential to cut down the emissions into the atmosphere to prevent the alarming rise of global temperatures.

The green house gases can survive in the atmosphere in their molecular state without getting affected by any external agents for a certain period. Here a term known as the atmospheric lifetime is defined which gives an estimation of the time required to restore stability once the natural balance is disturbed by increase in certain atmospheric species. It is given by:

$$
T=\frac{m}{\text { Fout }+L+D}
$$

where $m$ is the mass of the species in kilograms

$F_{\text {out }}$ is the natural flow of the species from the atmospheric system in $\mathrm{kg} / \mathrm{sec}$

$\mathrm{L}$ is the loss of the species due to chemical combination with other elements $\mathrm{kg} / \mathrm{sec}$

$\mathrm{D}$ is rate of deposition of the species from various sources ( in our case $\mathrm{CO}_{2}$ from thermal power plants ) in $\mathrm{kg} / \mathrm{sec}$.

This estimation is only a good approximation but cannot be entirely relied upon. Hence, since it is not possible to cut down the power generation to reduce emissions, the alternate way is optimize the generation while keeping the emissions to a minimum level.

\section{PROBLEM FORMULATION}

The objective of solving economic dispatch problem in an electric power system is to determine the generation levels for all online units which minimize the emission level of the system, while satisfying a set of constraints. This can be formulated as follows:

\subsection{Emission Equation}

The emission equation of a generating unit is usually described by a quadratic function of power output $\mathrm{P}_{\mathrm{i}}$ as follows:

$\mathrm{E}_{\mathrm{i}}\left(\mathrm{P}_{\mathrm{i}}\right)=\mathrm{d}_{\mathrm{i}} \mathrm{P}_{\mathrm{i}}^{2}+\mathrm{e}_{\mathrm{i}} \mathrm{P}_{\mathrm{i}}+\mathrm{f}_{\mathrm{i}} \mathrm{kg} / \mathrm{hr}$

where $d_{i}, e_{i}, f_{i}$ are the emission coefficients of an unit $i$.

\subsection{Power Balance Constraint}

The total generation must supply the online demand.

$$
\sum(P i)=P d
$$

where Pd is the load demand.

\subsection{Generator Limit Constraints}

There will be some upper and lower limits for any generating unit. The power generation of unit $n$ should be in between its minimum and maximum limits only.

where

$$
\mathrm{P}_{\mathrm{n}} \min <\mathrm{P}_{\mathrm{n}}<\mathrm{P}_{\mathrm{n}} \max
$$

$P_{n}$ min is the minimum limit of unit $n$

$\mathrm{P}_{\mathrm{n}}$ max is the maximum limit of unit $\mathrm{n}$.

\section{FIREFLY OPTIMIZATION TECHNIQUE}

The Fire Fly Optimization Algorithm is based on the biochemical and social behaviour of the fireflies. Fireflies produce luminescent flashes as a signal system to communicate with other fireflies, especially to prey attractions. The algorithm has 4 main assumptions. They are:

1. All the fire flies are unisexual, means there are no male and female fire flies as such.

2. Every fire fly communicates with the other flies using the luminous flashes.

3. The attraction is directly proportional to the brightness of the light that the fly emits and which is inversely proportional to the distance between them.

4. No fire fly can attract the brightest fire fly and in fact all the others are attracted to the brightest one.

In this algorithm all the fire flies initially will be at random locations in the search space. Based on the fitness values they produce the light with certain intensity proportional to its fitness. All the fireflies move towards the brighter fire fly and eventually an optimum solution is found in the search space.

The pseudo code for the Fire fly optimization algorithm is as follows:

Input :

$$
\begin{aligned}
& F(n), n=[n 1, n 2, n 3, \ldots \ldots \ldots . . \quad\{\text { objective function }\} \\
& S=\left[a_{k}, b_{k}\right] \text { for all } k=1,2,3, \ldots \ldots, n\{\text { constraints of the problem }\} \\
& F, G, B, \max _{\mathrm{i}}, \min _{\mathrm{i}} \quad\{\text { Algorithm inputs }
\end{aligned}
$$


Output:

$\mathrm{X}_{\mathrm{i} \text { min }} \quad$ \{Resultant global minima point $\}$

Begin;

For $\mathrm{i}=1$ to $\mathrm{F}$

$\mathrm{X}(\mathrm{i})=>$ Initialize the positions of the flies

End

Repeat

Begin

i $\min <=\arg \min _{\mathrm{i}} \mathrm{f}\left(\mathrm{x}_{\mathrm{i}}\right)$

$\mathrm{Xi} \min <=\arg \min _{\mathrm{xi}} \mathrm{f}\left(\mathrm{x}_{\mathrm{i}}\right)$

For $\mathrm{i}=1$ to $\mathrm{m}$ do

For $\mathrm{j}=1$ to $\mathrm{m}$ do

$$
\begin{aligned}
& \text { If } \mathrm{f}\left(\mathrm{x}_{\mathrm{j}}\right)<\mathrm{f}\left(\mathrm{x}_{\mathrm{i}}\right) \text { then }\{\text { move firefly } \mathrm{i} \text { towards }\} \\
& \mathrm{r}_{\mathrm{j}}<=\text { calculate distance }\left(\mathrm{x}_{\mathrm{i},} \mathrm{x}_{\mathrm{j}}\right) \\
& \mathrm{B}<=\mathrm{B}_{\mathrm{o}} \mathrm{e}^{-\mathrm{Gr}}\{\text { obtain attractiveness }\} \\
& \mathrm{U}_{\mathrm{i}}<=\text { Generate Random Vector }\left\{\min \mathrm{u}_{\mathrm{i}},\right.
\end{aligned}
$$

$\left.\max u_{\mathrm{i}}\right\}$

$$
\begin{aligned}
& \text { For } \mathrm{k}=1 \text { to } \mathrm{n} \text { do } \\
& \qquad \mathrm{X} \text { i } \min , \mathrm{k}<=\mathrm{X} \text { i min, } \mathrm{k}+\mathrm{U} \text { i min, } \mathrm{k}
\end{aligned}
$$$$
\text { End }
$$

$$
\text { End }
$$

End

End

$\mathrm{U}$ i $\min <=$ Generate Random Vector $\left\{\min \mathrm{u}_{\mathrm{i}}, \max \mathrm{u}_{\mathrm{i}}\right\}$

For $\mathrm{k}=1$ to $\mathrm{n}$ do

$$
\mathrm{Xi} \min , \mathrm{k}<=\mathrm{Xi} \min , \mathrm{k}+\mathrm{U} \mathrm{I} \min , \mathrm{k}
$$

\{best firefly should move randomly

End

Until stop condition true

End

\section{RESULTS AND EVALUATION}

The power system economic dispatch problem based on fire fly optimization technique is tested on standard 3 generator and six generator systems. Multiple generator limits and total emission level of the system is simulated in order to evaluate the correctness and quality of the method.

The emission constants and the generator limits of a 3 generator system are tabulated in TABLE I
TABLE I: EMISSION COEFFICIENTS AND POWER LIMITS OF 3 GENERATOR SYSTEM

\begin{tabular}{|l|l|l|l|l|l|}
\hline Generator & $\mathbf{D}_{\mathbf{i}}$ & $\mathbf{e}_{\mathbf{i}}$ & $\mathbf{f}_{\mathbf{i}}$ & Pmin & Pmax \\
\hline Unit 1 & 0.0126 & -1.355 & 22.983 & 20 & 200 \\
\hline Unit 2 & 0.01375 & -1.249 & 137.370 & 15 & 150 \\
\hline Unit 3 & 0.00765 & -0.805 & 363.704 & 18 & 180 \\
\hline
\end{tabular}

The emission constants and the generator limits of a 6 generator system are tabulated in TABLE II.

TABLE II: EMISSION COEFFICIENTS AND POWER LIMITS OF 6 GENERATOR SYSTEM

\begin{tabular}{|l|l|l|l|l|l|}
\hline Generator & $\mathrm{D}_{\mathrm{i}}$ & $\mathrm{e}_{\mathrm{i}}$ & $\mathrm{f}_{\mathrm{i}}$ & Pmin & Pmax \\
\hline Unit 1 & 0.0042 & 0.3300 & 13.86 & 10 & 125 \\
\hline Unit 2 & 0.0042 & 0.3300 & 13.86 & 10 & 150 \\
\hline Unit 3 & 0.0068 & -0.5455 & 40.26 & 35 & 225 \\
\hline Unit 4 & 0.0068 & -0.5455 & 40.26 & 35 & 210 \\
\hline Unit 5 & 0.0046 & -0.5112 & 42.96 & 130 & 325 \\
\hline Unit 6 & 0.0046 & -0.5112 & 42.96 & 125 & 315 \\
\hline
\end{tabular}

The simulations are done in MATLAB software. The results obtained for different loads for both 3 generator and 6 generator system are tabulated below.

TABLE III: COMPARISION OD FIRE FLY OPTIMIZATION WITH OTHER TECHNIQUES UNDER VARIOUS LOAD CONDITIONS FOR THREE GENERATOR SYSTEM

\begin{tabular}{|c|l|l|l|}
\hline Generation MW & \multicolumn{3}{|c|}{ Total Emission (Kg/hr) } \\
\cline { 2 - 4 } & $\begin{array}{l}\text { Proposed } \\
\text { Method }\end{array}$ & $\begin{array}{l}\text { Particle Swarm } \\
\text { Optimization[1] }\end{array}$ & $\begin{array}{l}\text { Conventional } \\
\text { Method [1] }\end{array}$ \\
\hline 200 & $\mathbf{4 4 6 . 3 0 4}$ & 521.0815 & 529.26 \\
\hline 250 & $\mathbf{4 7 2 . 1 8 5 9}$ & 583.7942 & 597.499 \\
\hline 300 & $\mathbf{5 1 5 . 7 5 0 6}$ & 679.6378 & 684.826 \\
\hline 350 & $\mathbf{5 7 6 . 9 8 7}$ & 762.1878 & 791.24 \\
\hline 400 & $\mathbf{6 5 5 . 9 0 8 3}$ & 878.5765 & 916.742 \\
\hline
\end{tabular}

Tables IV and V show the comparison of the performance of the proposed approach with the Particle Swarm Optimization Technique and conventional approach for both three generator and six generator test systems for various values of load demand. The results depicts that the proposed approach shows very good improvement over PSO and conventional approach. Especially the margin that we have gained in large in 3 generator system. 
TABLE IV: COMPARISION OD FIRE FLY OPTIMIZATION WITH OTHER TECHNIQUES UNDER VARIOUS LOAD CONDITIONS FOR SIX GENERATOR SYSTEM

\begin{tabular}{|c|c|c|c|}
\hline \multirow{2}{*}{ Generation MW } & \multicolumn{3}{|c|}{ Total Emission (Kg/hr) } \\
\cline { 2 - 4 } & $\begin{array}{c}\text { Proposed } \\
\text { Method }\end{array}$ & $\begin{array}{c}\text { Particle } \\
\text { Swarm } \\
\text { Optimization } \\
{[1]}\end{array}$ & $\begin{array}{c}\text { Conventional } \\
\text { Method [1] }\end{array}$ \\
\hline 500 & $\mathbf{2 5 2 . 3 8 8 9}$ & 251.822 & 261.634 \\
\hline 600 & $\mathbf{3 2 7 . 8 6 4 9}$ & 329.3599 & 338.992 \\
\hline 700 & $\mathbf{4 1 6 . 9 9 5 6}$ & 428.5095 & 434.38 \\
\hline 800 & $\mathbf{5 2 2 . 7 5 5 7}$ & 540.2801 & 547.796 \\
\hline 900 & $\mathbf{6 4 5 . 1 1 9 5}$ & 650.4240 & 679.24 \\
\hline 1000 & $\mathbf{7 8 4 . 6 9 9 2}$ & 793.7640 & 828.72 \\
\hline 1100 & & & 996.224 \\
& $\mathbf{9 4 5 . 5 6 7 5}$ & 953.3311 & \\
\hline & & & \\
\hline
\end{tabular}

TABLE V: INDIVIDUAL POWERS OF THE THREE GENERATORS FOR VARIOUS DEMANDS

\begin{tabular}{|c|c|c|c|}
\hline Generation MW & \multicolumn{3}{l|}{ Individual Powers } \\
\cline { 2 - 4 } & Unit-1 & Unit-2 & Unit-3 \\
\hline 200 & 67.295 & 57.812 & 74.892 \\
\hline 250 & 81.328 & 70.671 & 98.004 \\
\hline 300 & 95.359 & 83.5298 & 121.115 \\
\hline 350 & 109.39 & 96.386 & 144.224 \\
\hline 400 & 123.42 & 109.244 & 167.334 \\
\hline
\end{tabular}

TABLE VI: INDIVIDUAL POWERS OF THE SIX GENERATORS FOR VARIOUS DEMANDS

\begin{tabular}{|c|c|c|c|c|c|c|}
\hline Gen MW & \multicolumn{5}{|l|}{ Individual Powers } \\
\cline { 2 - 7 } & Unit1 & Unit2 & Unit3 & Unit4 & Unit5 & Unit6 \\
\hline 500 & 35.92 & 35.92 & 86.56 & 85.56 & 130.0 & 125.0 \\
\hline 600 & 56.97 & 56.97 & 99.56 & 99.56 & 143.4 & 143.4 \\
\hline 700 & 76.73 & 76.73 & 111.7 & 111.7 & 161.4 & 161.4 \\
\hline 800 & 96.48 & 96.48 & 123.9 & 123.9 & 179.5 & 179.5 \\
\hline 900 & 116.2 & 116.2 & 136.1 & 136.1 & 197.5 & 197.5 \\
\hline 1000 & 125.0 & 138.7 & 150.0 & 150.0 & 218.0 & 218.0 \\
\hline 1100 & 125.0 & 150.0 & 167.9 & 167.9 & 244.5 & 244.5 \\
\hline
\end{tabular}

Figure 1 and Figure 2 show the comparison graphs for emission of carbon dioxide for three generator and six generator test system. The graphs contain the emission $(\mathrm{Kg} / \mathrm{hr})$ on the $\mathrm{Y}$ axis and Load demand (MW) on the $\mathrm{X}$ axis. It is clear from the graphs that the proposed algorithm is better than the conventional approaches.

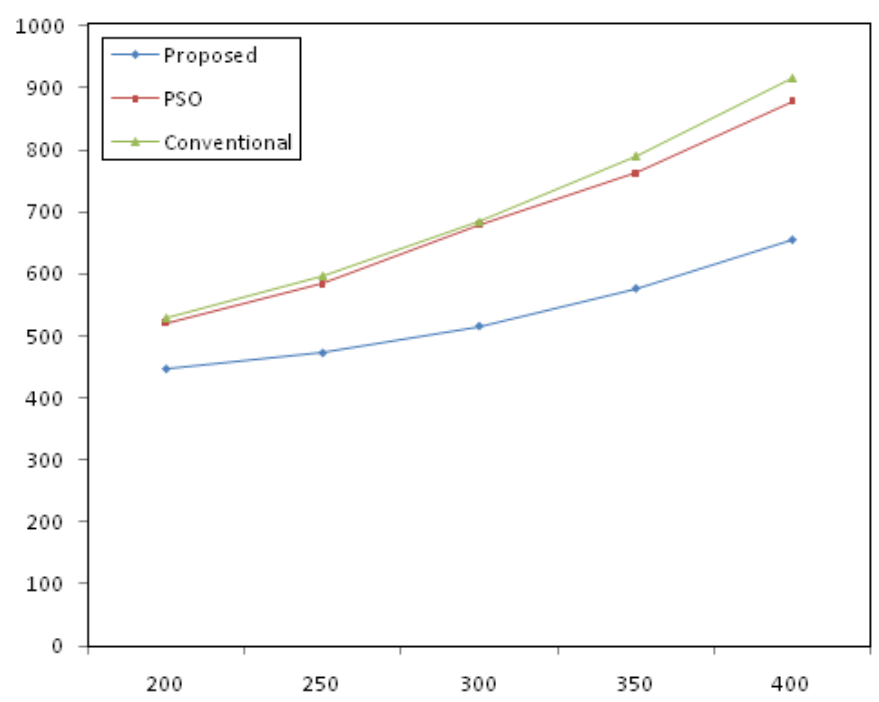

Fig. 1 Comparison of emissions for 3 Gen system

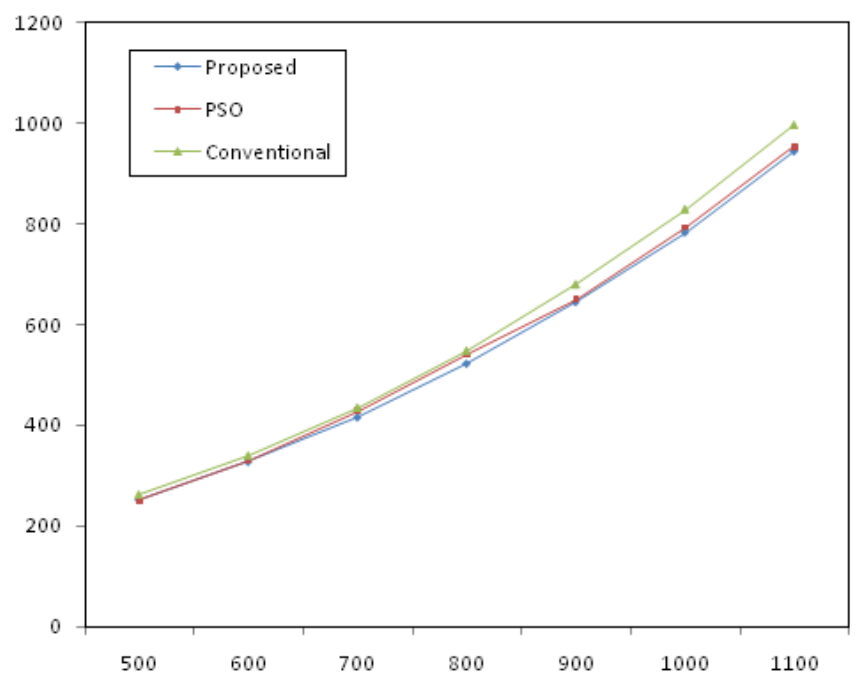

Fig. 2 Comparison of emissions for 6 Gen system

\section{REFERENCES}

[1] K.Senthil, K. Manikandan, Ignatius A Herman, L.Sarvanan, "Reduction of Carbon Dioxide Emission in Thermal Power Plaants by using Paticle Swarm Optimization Technique," International journal of Computer Applications(0975-8887), Volume-3, June2010 
[2] Mitra, A.P. (ed), Green house Gas emissions in India: 1992 update, Scientific report No.4, Centre for Global Change, National Physics Laboratory, New Delhi, 1992.

[3] K.P.Wong and C.C.Fung, Simulated Annealing based Economic Load Dispatch, IEEE proceedings on Generation, Transmission and Distribution-C, Vol.140, No.6, Nov 1993, pp 509-513.

[4] Easom, E: A Survey of global optimization techniques. Master's Thesis, University of Louisville (1990)

[5] C.E.Lin and G.L.Viviani, "Hierarchical Economic Dispatch for piece wise quadratic function," IEEE Trans. Power Apparatus Syst., vol.PAS-103, pp. 1170-1175,June 1984W.

[6] K.Y.Lee,A.S.Yome and J.H.Park, "Adaptice Hopfield Networks for Economic Load Dispatch.” IEEE Trans. Power Apparatus Syst., vol. 13, pp.519-526,May 1998.

[7] Yang, X.S: Nature- Inspired Metaheuristic Algorithms. Luniver Press (2008).
[8] P.Venkatesh, K.Y.Lee, "Multi-Objective Evolutionary Programming for Economic Emission Dispatch Problem", Power and Energy Society General Meeting-Conversion and Delivery of Electrical Energy in the $21^{\text {st }}$ Century, 2008,pp.1-8.

[9] M.Basu, "A simulated annealing based goal attainment method for economic emission laod dispatch of fixed head hydrothermal power systems", Electrical Power and Energy Systems, 27, 2005, pp.147-153

[10] L.Wang, C.Singh, "Reserve-constrained multiarea environmental / economic dispatch based on particle swarm optimization with local search", Engineering Applications of Artificial Intelligence, 22, 2009, pp.298-307.

[11] M.Basu, "Dynamic economic emission dispatch using nondominated sorting genetic algorithm-II", Electrical Power and Energy Systems, 30, 2008, pp.140-149.

[12] Babu, B.G.., Kannan. M, : Lightening bugs, Resonance 7(9) (2002) 146-158. 